\title{
Controlling Epileptiform Activity with Organic Electronic Ion Pumps
}

\author{
Adam Williamson, Jonathan Rivnay, Loig Kergoat, Amanda Jonsson, Sahika Inal, Ilke Uguz, \\ Marc Ferro, Anton Ivanov, Theresia Arbring Sjöström, Daniel Simon, Magnus Berggren, \\ George G. Malliaras and Christophe Bernard
}

\section{Linköping University Post Print}

\section{Tweet}

N.B.: When citing this work, cite the original article.

Original Publication:

Adam Williamson, Jonathan Rivnay, Loig Kergoat, Amanda Jonsson, Sahika Inal, Ilke Uguz, Marc Ferro, Anton Ivanov, Theresia Arbring Sjöström, Daniel Simon, Magnus Berggren, George G. Malliaras and Christophe Bernard, Controlling Epileptiform Activity with Organic Electronic Ion Pumps, 2015, Advanced Materials, (27), 20, 3138-3144.

http://dx.doi.org/10.1002/adma.201500482

Copyright: Wiley-VCH Verlag http://www.wiley-vch.de/publish/en/

Postprint available at: Linköping University Electronic Press http://urn.kb.se/resolve?urn=urn:nbn:se:liu:diva-119247 


\section{WILEY-VCH}

DOI: $10.1002 /(($ manuscript number $))$

\section{Article type: Communication}

\section{Controlling Epileptiform Activity with Organic Electronic Ion Pumps}

Adam Williamson, Jonathan Rivnay, Lö̈g Kergoat, Amanda Jonsson, Sahika Inal, Ilke Uguz, Marc Ferro, Anton Ivanov, Theresia Arbring-Sjöström, Daniel T. Simon, Magnus Berggren, George G. Malliaras ", Christophe Bernard ${ }^{*}$

Dr. Adam Williamson ${ }^{[+]}$, Dr. Anton Ivanov, Prof. Christophe Bernard

l'Université d'Aix-Marseille, INS, 13005 Marseille, France

Inserm, UMR_S 1106, 13005 Marseille, France

Dr. Jonathan Rivnay ${ }^{[+]}$, Dr. Sahika Inal, Ilke Uguz, Marc Ferro, Prof. George G. Malliaras

Department of Bioelectronics, Ecole Nationale Supérieure des Mines, CMP-EMSE, MOC, 13541 Gardanne, France

Dr. Loïg Kergoat ${ }^{[+]}$, Amanda Jonsson, Theresia Arbring-Sjöström, Prof. Daniel T. Simon, Prof. Magnus Berggren

Laboratory of Organic Electronics, Linköping University, Department of Science and Technology, 60174 Norrköping, Sweden

E-mail: Christophe.BERNARD@univ-amu.fr \& malliaras@emse.fr

${ }^{[+]}$These three authors contributed equally to this work

Keywords: Organic Bioelectronics, Organic Electronic Ion Pump, PEDOT:PSS, Neuroengineering

Drugs constitute the classical therapeutic approach to treat diseases. Newly designed active substances can be very promising during preclinical testing, but later fail in the clinic because of their toxicity, side effects, rapid elimination/degradation, or failure to reach the desired target. Additionally, drugs are not usually administered specifically to the region of the body affected by the pathology. As a result, they can act elsewhere and have deleterious, undesired effects. In the case of neurological disorders, the situation is more complex as drugs need to cross the blood brain barrier before reaching their targets in the brain. ${ }^{[1,2]}$ In addition, the expression of multidrug transporters can effectively transport drugs back to the blood stream limiting their action in the nervous system. ${ }^{[3,4]}$ Novel strategies have been developed to 


\section{WILEY-VCH}

circumvent these limitations in the field of neurological disorders. They include optogenetics, which has been used to control epilepsy $y^{[5,6,7]}$ and psychiatric disorders ${ }^{[8,9]}$, and designer receptors, which are exclusively active by designer drugs. ${ }^{[10,11,12]}$ These techniques allow ondemand interventions, where and when they are needed. However, both approaches require the viral or non-viral transfection of xenomolecules ${ }^{[53,54]}$, which still limits their translation to the clinic. ${ }^{[13]}$ In the immediate future, drugs still remain the best mode of action; therefore, progress must be made to by-pass all the above-mentioned problems. An ideal solution would be to deliver drugs directly where they are needed, on demand. In this Communication we use an Organic Electronic Ion Pump (OEIP) to deliver an active substance to tissue slices and control epileptiform activity. We use three different models to induce epileptiform activity and show that delivery of gamma-aminobutyric acid (GABA) results in quick and localized suppression of this activity. As the integration of OEIPs on implantable probes is rather straightforward, we believe that these devices have great potential in drug delivery in the brain, and in particular in delivery of anti-epileptic active substances.

We used epilepsy as a model system to test the device. Epilepsy affects $1 \%$ of the world population and remains drug-resistant in $30 \%$ of the cases. ${ }^{[18,19]}$ Epilepsy is a prototypical example for which drugs have failed in the clinic because of their toxicity, side effects, or failure to cross the blood brain barrier, despite having strong antiepileptic effects. ${ }^{[20,21]}$ Controlling drug-resistant epilepsy may still be achieved with these compounds if they could be delivered locally. As a first step in this direction, we used hippocampal slices in which several pharmacological manipulations can be used to evoke epileptiform activity. Lowering the extracellular concentration of $\mathrm{Mg}^{2+}$ or blocking $\mathrm{K}^{+}$channels with 4-aminopyridine (4AP) in the perfusion medium produces epileptiform activity that is resistant to common antiepileptic drugs. ${ }^{[22,23]}$ In order to test the efficacy of the OEIP, we chose to deliver GABA, an endogenous neurotransmitter, which can have an inhibitory effect via its action on $\mathrm{GABA}_{\mathrm{A}}$ 


\section{WILEY-VCH}

and $\mathrm{GABA}_{\mathrm{B}}$ receptors. In adult neurons, the activation of $\mathrm{GABA}_{\mathrm{A}}$ receptors leads to $\mathrm{Cl}^{-}$influx into the cell, hyperpolarizing the cell membrane. In addition, the opening of these channels decreases the membrane resistance, creating a shunt effect, and limiting the effectiveness of excitatory inputs. The net effect is to decrease the firing probability of the cell. The advantages of using GABA are that it is endogenous and that it is quickly taken up and metabolized. ${ }^{[24,25]}$ It is also particularly relevant in the context of epilepsy since many antiepileptic drugs have been designed to boost GABAergic neurotransmission. ${ }^{[26,27]}$

OEIPs can be used to deliver ions and small charged molecules, such as neurotransmitters, with high spatial resolution, to stimulate cell activity locally. ${ }^{[50,51]}$ The OEIP key component is a cation exchange membrane (CEM), a polyanion, which, because of its high concentration of fixed negative charges, is selectively permeable to cations. This inclusion of cations and exclusion of anions is valid as long as the ionic concentrations of the electrolytes in contact with the CEM are low compared to the concentration of fixed charges in the CEM. To "pump" ions from one electrolyte, through the CEM to the other electrolyte, a voltage is applied across the CEM, and cations in the positively addressed electrolyte are electrophoretically transported through the polyanion. Since anions are excluded from the CEM, the majority of the current through the CEM is due to cation drift (typically for a fixed charge concentration of $1 \mathrm{M}$ in a CEM and $0.1 \mathrm{M}$ electrolytes, $99 \%$ of the mobile ions in the CEM are cations and $1 \%$ are anions). This means that the number of cations that are released at the target electrolyte can be calculated from the current, with $1 \mu \mathrm{A}$ translating to a delivery rate of 10 $\mathrm{nM} / \mathrm{second}$. To run an ionic current through the CEM, two electrodes that can convert an electronic current into an ionic current are needed. We use poly(3,4-ethylenedioxythiophene) doped with polystyrene sulfonate (PEDOT:PSS) electrodes, labeled source electrode and target electrode (Figure 1). 


\section{WILEY-VCH}

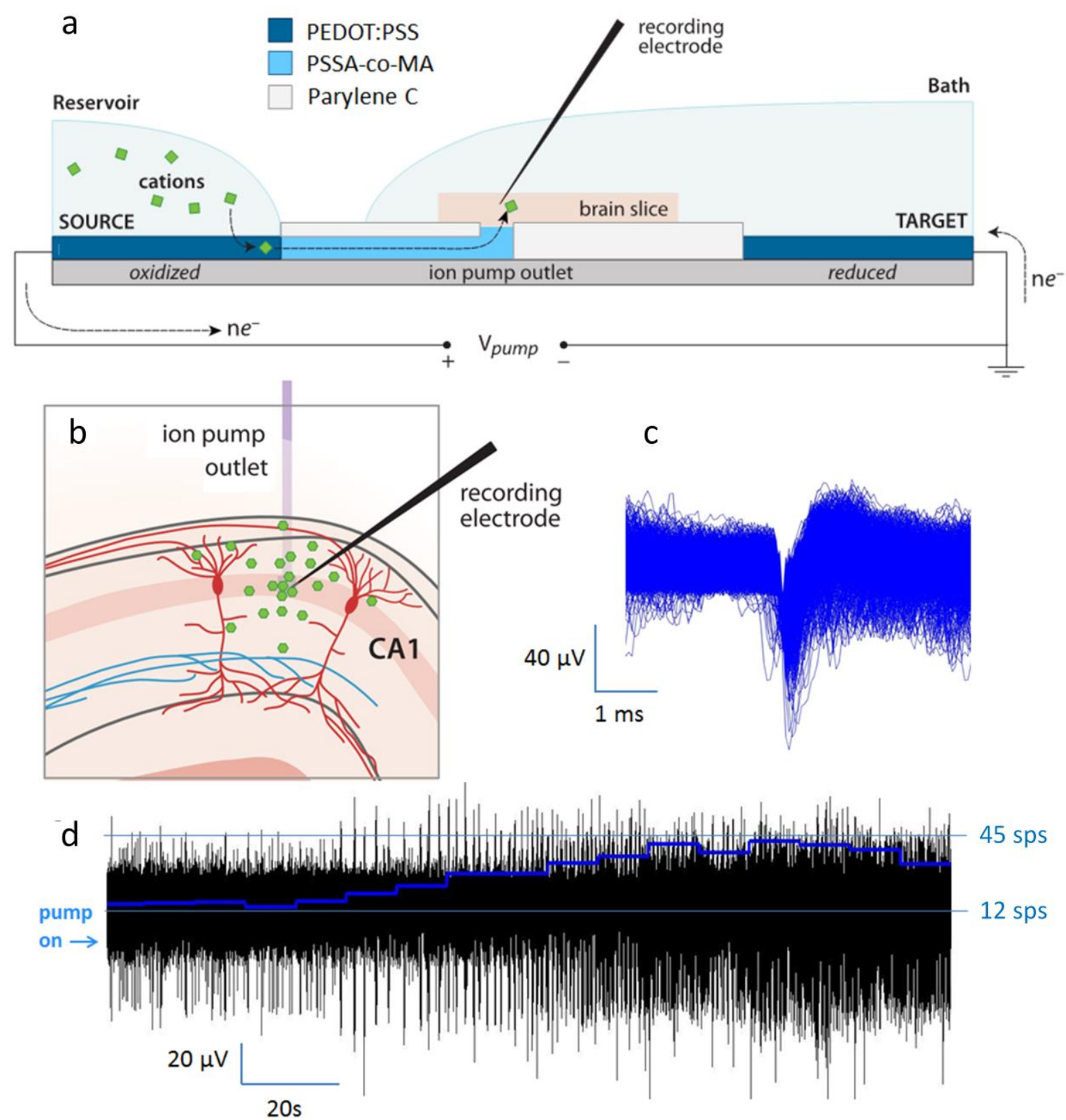

Figure 1. OEIP delivery of $\mathrm{K}^{+}$directly to neural tissue to induce hyperexcitability a) Due to an applied bias voltage, $V_{\text {pump }}$, cations are electrophoretically transported from the reservoir towards the target, through a CEM made of PSSA-co-MA, and released at the outlets below the tissue. For each ion being delivered, an electron is transferred from the source electrode to the target electrode, oxidizing the source and reducing the target. b) The outlets of the pump are located below the pyramidal cell layer of CA1 area of the mouse hippocampus. A tungsten recording electrode is inserted in the pyramidal cell layer over the outlet of interest to record the field potential and unitary spikes. c) The electrode recorded spontaneous firing. Action potentials were sorted from the complete recording to obtain the change in mean firing rate, determining the approximate number of spikes per second (sps). d) The pump was turned on at the beginning of the displayed recording, as indicated. After approximately 1 minute a significant increase in mean firing rate from $12 \mathrm{sps}$ to over $40 \mathrm{sps}$ was measured (blue trace).

The source electrode is positively biased, which means that holes are injected into the PEDOT

of this electrode. To remain charge neutral, cations leave the PEDOT:PSS source electrode as 


\section{WILEY-VCH}

the charge of the PEDOT increases due to the injection of holes. The target electrode is negatively biased, which means that holes are extracted from the PEDOT of this electrode. To remain charge neutral, cations move into the PEDOT:PSS target electrode as the charge of the PEDOT decreases due to the extraction of holes.

The reaction at the positive source electrode can be described by:

$$
\operatorname{PEDOT}^{\mathrm{x}+}: \mathrm{mM}^{+}: \operatorname{PSS}^{(\mathrm{x}+\mathrm{m})-} \rightarrow \operatorname{PEDOT}^{(\mathrm{x}+\mathrm{n})+}:(\mathrm{m}-\mathrm{n}) \mathrm{M}^{+}: \mathrm{PSS}^{(\mathrm{x}+\mathrm{m})-}+\mathrm{ne}^{-}+\mathrm{nM}^{+}
$$

where $\mathrm{M}^{+}$is an arbitrary monovalent cation in the electrolyte, $\mathrm{x}, \mathrm{m}$ and $\mathrm{n}$ are integers, and $\mathrm{e}^{-}$is an electron. At the negative target electrode the reverse reaction takes place:

$$
\operatorname{PEDOT}^{\mathrm{y}+}: \mathrm{pM}^{+}: \operatorname{PSS}^{(\mathrm{y}+\mathrm{p})-}+\mathrm{ne}^{-}+\mathrm{nM}^{+} \rightarrow \operatorname{PEDOT}^{(\mathrm{y}-\mathrm{n})+}:(\mathrm{p}+\mathrm{n}) \mathrm{M}^{+}: \operatorname{PSS}^{(\mathrm{y}+\mathrm{p})-}
$$

where $y$ and $p$ are integers. The lifetime of the device is limited by the capacity of the PEDOT in electrodes. The device can keep transporting ions, with the above mentioned electrode reactions, as long as there is PEDOT in the source and target to be oxidized and reduced, respectively. An estimate of device lifetime can be found in the Supplementary section. The OEIP used in this work (Fig. 1a) has a reservoir electrolyte that contains the cations to be transported $\left(\mathrm{K}^{+}\right.$or $\left.\mathrm{GABA}^{+}, 40 \mathrm{mM}(\mathrm{aq})\right)$ to the chamber containing the neural tissue. The CEM is made from the polyanion poly(styrene sulfonate-co-maleic acid) (PSSA-co-MA) cross-linked with poly(ethylene glycol) (PEG) and is patterned into a large channel that then splits into an array of 32 separate outlets, each $20 \mu \mathrm{m}$ wide. The pyramidal cell layer of the CA1 area of the mouse hippocampus was placed directly above the outlets of the OEIP. A tungsten recording electrode was then inserted into the pyramidal cell layer directly above one 


\section{WILEY-VCH}

outlet to record close to the outlet. A voltage was sourced to induce a cationic current through the OEIP, and recorded the activity resulting from the cation delivery.

In order to demonstrate the ability of the pump to deliver ions and modify neuronal function, we first used local $\mathrm{K}^{+}$delivery, a procedure known to induce hyperexcitability in mouse hippocampal slices. ${ }^{[29,30]}$ The outlet of the pump was placed in direct contact with the stratum pyramidale (SP) of the hippocampal CA1 area (Fig. 1b). A tungsten recording electrode was inserted in SP, directly above the outlet of the pump, to provide immediate electrophysiological recordings of pyramidal cell firing (Fig. 1b) and assess the effects of $\mathrm{K}^{+}$ delivery. Recordings taken during $\mathrm{K}^{+}$delivery (black trace) are shown (Fig. 1d), with the corresponding changes in mean firing rate superimposed (blue trace). Approximately $60 \mathrm{~s}$ after switching on the ion pump, there was a clear increase in firing rate. Assuming similar delivery from the all outlets, the measured current through the device during the applied $20 \mathrm{~V}$ bias corresponds to a delivery of $4.08 \mathrm{nM} /$ second/outlet given an ideally permselective CEM. The details of calculations can be found in the Supplementary section. The concentration of ions in an area around the outlets can be estimated by modeling the diffusion of ions from the outlets in a half-sphere with radius equal to the maximum diffusion length of the ion during the delivery time. This concentration after $60 \mathrm{~s}$ of delivery is increased approximately $2.9 \mathrm{mM}$ above the normal concentration in the artificial cerebrospinal fluid (ACSF). This concentration is an overestimate since it does not take into account the uptake mechanisms of $\mathrm{K}^{+}$by glial cells. ${ }^{[31]}$ To verify that the increase in activity was not due to the powering of the electronic device itself, we switched on the pump with no cation in the reservoir only DI water. This did not increase or decrease neuronal activity (not shown). For comparison, direct addition of potassium chloride $(3.5 \mathrm{mM})$ to the perfusion medium (with the ion pump turned off), resulted in similarly increased neuronal activity (compare Fig. 1d and Fig. 2c). We 


\section{WILEY-VCH}

conclude that neuronal activity can be manipulated on-demand by the local delivery of cations with the OEIP.

To demonstrate the ability of the devices to control epileptiform activity, we used three different models: high $\mathrm{K}^{+},{ }^{[29]}$ low $\mathrm{Mg}^{2+},{ }^{[32]}$ and $4 \mathrm{AP} \cdot{ }^{[33]}$ GABA has an acidity (pKa) of 4.23 (carboxyl, $\mathrm{COO}^{-}$) and 10.43 (amino, $\left.{ }^{+} \mathrm{H}_{3} \mathrm{~N}\left(\mathrm{CH}_{2}\right)_{3}\right)$. We added GABA to DI water in the reservoir of the device, resulting in a $\mathrm{pH}$ of 6.67 . Taking into account that the $\mathrm{pH}$ inside the PEDOT:PSS is lower, this gives positively charged ${ }^{+} \mathrm{H}_{3} \mathrm{~N}\left(\mathrm{CH}_{2}\right)_{3} \mathrm{COOH}$ ions for delivery.

a
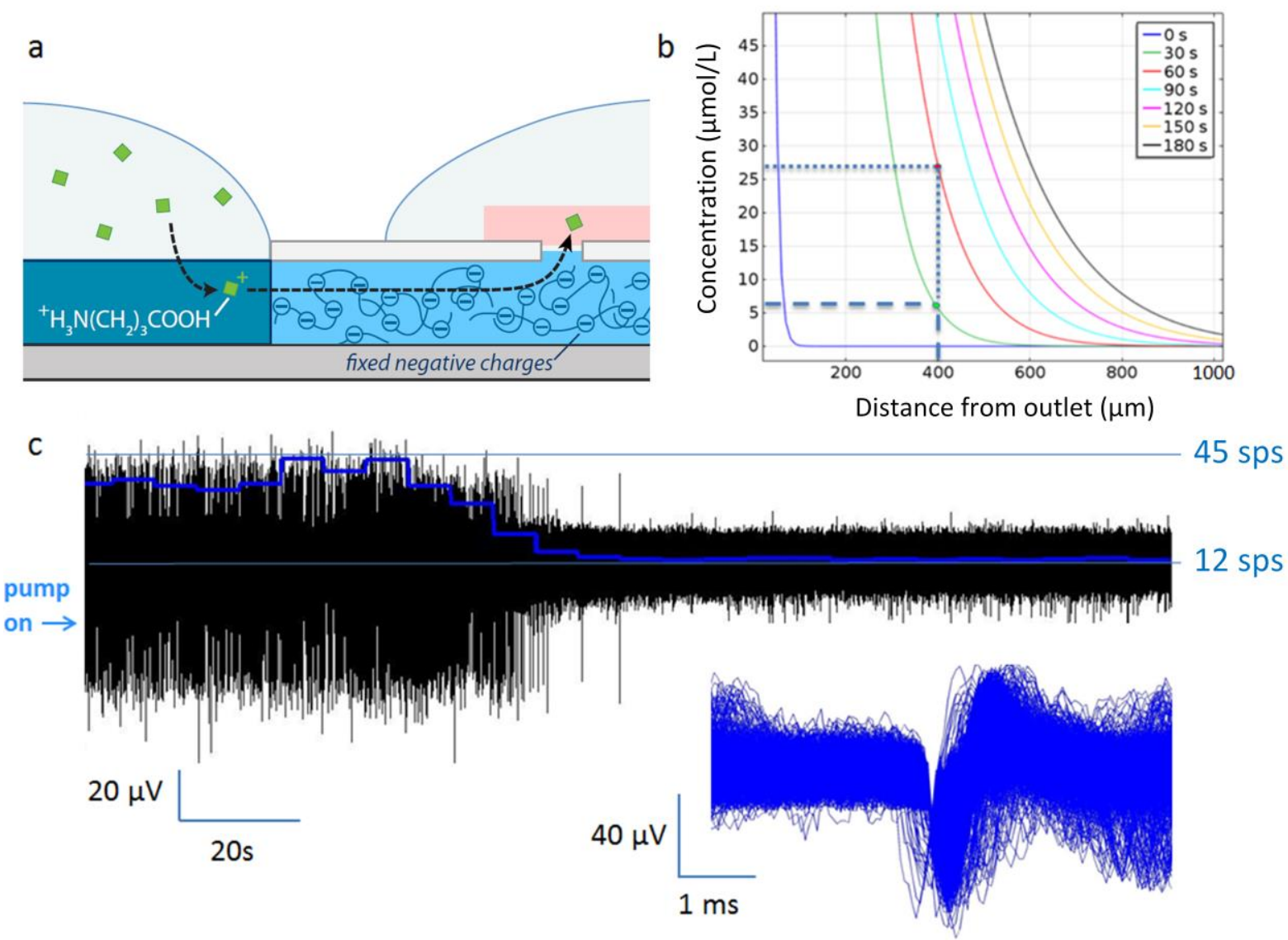
ps sps

Figure 2. OEIP delivery of GABA to suppress hyperexcitability. Hyperexcitability was induced by adding $3 \mathrm{mM}$ $\mathrm{KCl}$ to the perfusion. a) Only positive GABA ions can be delivered through the CEM with its matrix of fixed negative charges. b) Numerical simulations of GABA concentration as it evolves vs distance from one outlet carrying an ionic current ${ }^{52}$ of $30 \mathrm{nA}$ are consistent with the analytical estimations made in the Supplementary section. $400 \mu \mathrm{m}$ at 30 seconds is highlighted, the maximum distance of the recording electrode from the outlet, giving a concentration of approximately $6 \mu \mathrm{mol} / \mathrm{L}$ of GABA. This concentration is enough to begin suppressing activity. c) Spikes were sorted from the complete recording to obtain the change in mean firing rate. The pump was turned on at the beginning of the displayed recording, as indicated. After approximately 1 minute, corresponding to a concentration of $26 \mu \mathrm{mol} / \mathrm{L}$ of GABA from simulations, a significant decrease in mean firing rate (blue trace) was observed. 


\section{WILEY-VCH}

To demonstrate the delivery and effect of these GABA ions, hyperactivity was first induced by the addition of extra potassium chloride to the perfusion (Figure 2), elevating the external concentration of $\mathrm{K}^{+}$from $3.5 \mathrm{mM}$ to $7 \mathrm{mM}$. The tungsten recording electrode was again located in CA1, above the ion pump outlet. The OEIP was then turned on. After approximately $60 \mathrm{~s}$ of pumping, CA1 pyramidal cell hyperactivity was suppressed (Fig. 2c). The delivery of GABA had no noticeable negative effects on the pyramidal cells, as activity returned to its original levels when the pump was turned-off (Supplementary Fig. 1).

We obtained similar results in the low $\mathrm{Mg}^{2+}$ model. As seen in Figure 3 (top panels), the ion pump was again placed under CA1 SP with a corresponding tungsten recording electrode. For additional comparison, a second tungsten electrode was located in the SP of the CA3 area. Epileptiform discharges were abolished within one minute of pumping in the CA1 area, while remaining unaffected in the $\mathrm{CA} 3$ region. This demonstrates that the ion pump can control the activity of a given region without interfering with the activity of the nearby region. We chose to control the CA1 region, because the axons from the pyramidal neurons of CA1 do not extend back to CA3. This means that modification in the firing rate of neurons in CA1 cannot directly affect the firing of CA3 pyramidal cells. Finally, delivering GABA also abolished epileptiform activity induced by 4AP (Fig. 3, bottom panels).

In these experiments, the delivery of GABA was estimated to be 1.75 picomol/second/outlet, corresponding to a local change of $4.5 \mu \mathrm{M}$ extracellularly in CA1 (calculation details in the Supplementary section). This concentration change is in the same order of magnitude of known quantities of extracellular GABA able to inhibit spontaneous activity, typically between 7 and $20 \mu \mathrm{M} \cdot{ }^{[34]}$ Once completely diluted in the $500 \mathrm{ml}$ perfusion, this delivered GABA is at a concentration of $3.36 \mathrm{nM}$, essentially insignificant. Hence, the effect of GABA 


\section{WILEY-VCH}

is due to its direct diffusion into the neuronal tissue, and not by its dilution into ACSF, a conclusion supported by the lack of effect on CA3 pyramidal cell activity.

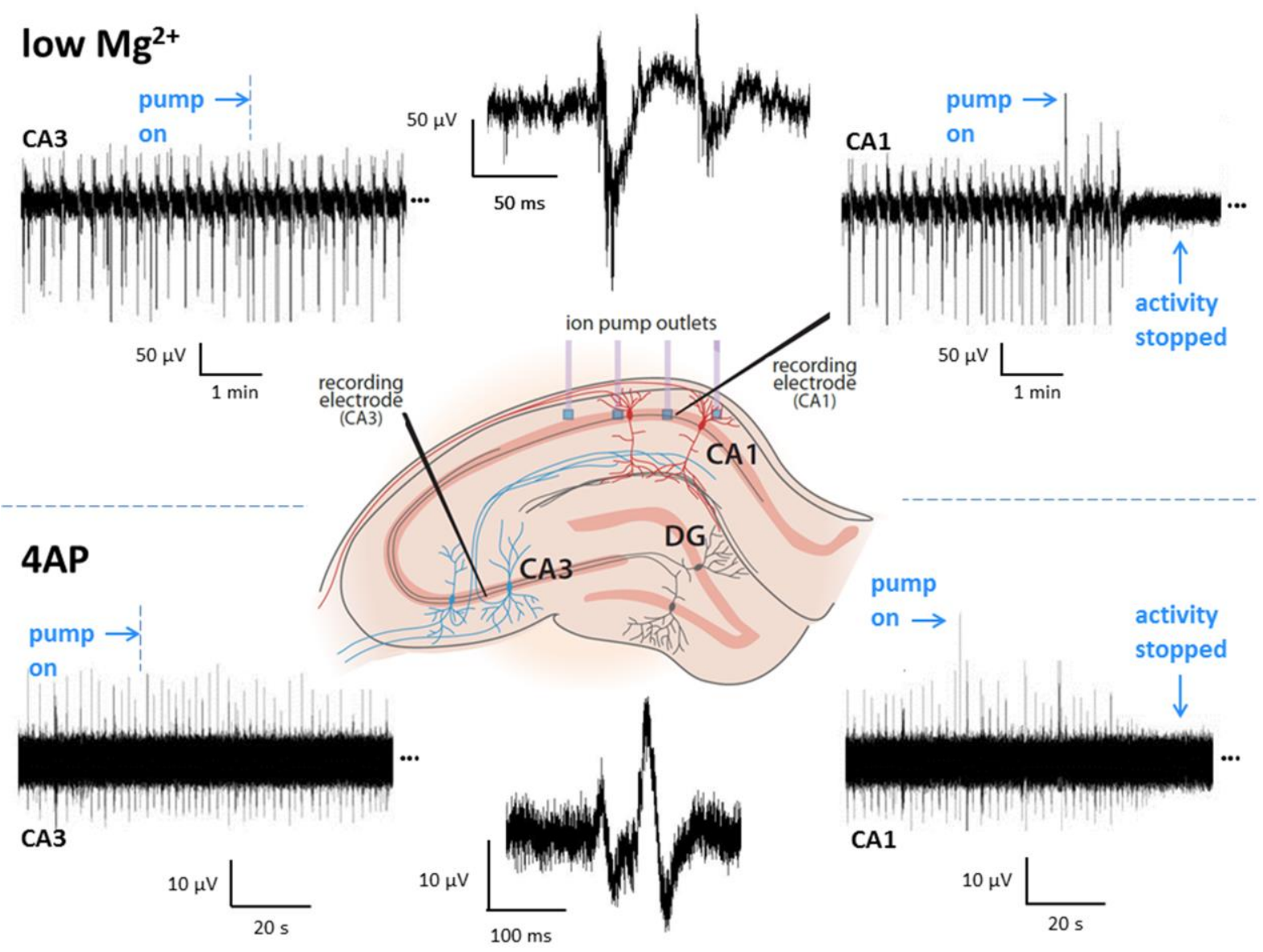

Figure 3. Suppression of epileptiform activity in the hippocampus with OEIPs. Targeted delivery of GABA from an ion pump located in the CA1 of a mouse hippocampal slice locally inhibits epileptiform activity induced in low $\mathrm{Mg}^{2+}$ ACSF (top panels) or in the presence of 4AP (bottom panels). The middle traces shows examples of individual epileptiform discharges (field potential) recorded in both conditions. Note that epileptiform discharges stopped in CA1 (right panels) where the pump outlets were located $1 \mathrm{~min}$ after turning on the pump, but not in CA3 (left panels), which was not exposed to GABA. A small artifact was seen in CA1, the location of the pump, when the pump was turned on, no artifact was seen in CA3.

We have shown that an OEIP can abolish abnormal electrophysiological activity by ondemand, local delivery of the inhibitory neurotransmitter GABA. Although the mechanisms underlying hyperexcitability induced by high-levels of $\mathrm{K}^{+}$, low $\mathrm{Mg}^{2+}$, and $4 \mathrm{AP}$ are different, GABA delivery successfully blocked the pathological activity. This means that, despite the fact that there are multiple ways to generate hyperexcitability, ${ }^{[35]}$ local delivery of GABA may work as a general way to control epileptiform activity. This is consistent with the fact that 


\section{WILEY-VCH}

seizures are prevented by GABA boosters in many patients. ${ }^{[36]}$ Studies of such epileptiform propagation in vitro clearly show that, before the epileptiform wavefront, there are very large amplitude inhibitory currents. ${ }^{[38]}$ The progressive loss of these inhibitory currents to pyramidal cells coincides with the progressive increase in the propagation of epileptiform activity. Since this loss of inhibitory control occurs when GABAergic neurons enter into a depolarization block after the onset of epileptiform discharges ${ }^{[35]}$, the local delivery of GABA could supplement the deficit of GABAergic neuronal activity and restore inhibitory restraint.

Whether the same effect can be obtained in vivo in chronic models of epilepsy remains to be determined. Transferring OEIP technology to the clinic is justified in drug resistant patients with partial onset epilepsy if neurosurgery cannot be performed (for example if it would remove/damage the eloquent cortex). The pumps could be incorporated into the electrodes routinely used in the clinic for long-term deep brain stimulations. The materials and fabrication scheme employed for the in vitro experiments used here for validation are compatible with similar approaches we have used to develop mechanically flexible organic bioelectronic devices for in vivo measurements. ${ }^{[47,48]}$ Namely, the ion pump can be fabricated on a parylene-C support that would impart a low profile, conformability, implantability and durability, ${ }^{[49]}$ and which can also incorporate electrophysiology and selective biomolecule/ion sensors. Moreover, in contrast to microfluidic delivery devices, OEIPs deliver molecules without any fluid flow and thus with negligible increase in local pressure, which is a requirement in the brain.

In conclusion, we fabricated organic electronic ion pumps using the conducting polymer PEDOT:PSS and a polyanionic copolymer. We used these devices to deliver GABA to tissue slices and demonstrated that epileptiform activity, induced using three different models, can be successfully controlled. These results show that organic electronic ion pumps represent a 


\section{WILEY-VCH}

technological breakthrough for local and timed delivery of active molecules that cannot be delivered in a systemic way.

\section{Experimental Section}

Electrophysiological recordings in vitro.

All protocols have been approved by the Institutional Animal Care and Use Committee of INSERM. All experiments were repeated twice. Electrophysiological recordings were made in the CA1 and CA3 of the mouse hippocampus. After decapitation of anesthetized mice, brains were rapidly extracted (postnatal day 14 to 18). Transverse hippocampal slices $(350 \mu \mathrm{m})$ were prepared using a vibratome. Freshly-cut slices were placed in a chamber and perfused with oxygenated $\left(95 \% \mathrm{O}_{2} / 5 \% \mathrm{CO}_{2}\right)$ artificial cerebrospinal fluid (ACSF) (126 mM $\mathrm{NaCl}, 3.5 \mathrm{mM} \mathrm{KCl}, 2 \mathrm{mM} \mathrm{CaCl}_{2}, 1.3 \mathrm{mM} \mathrm{MgCl}_{2}, 1.2 \mathrm{mM} \mathrm{NaH}_{2} \mathrm{PO}_{4}, 26.2 \mathrm{mM} \mathrm{NaHCO}$, and $10 \mathrm{mM}$ glucose). Slices were maintained in the chamber at room temperature and allowed to recover for one hour prior to experimental use. After this period of recovery, slices were transferred with a pipette to the surface of the ion pump. The chamber containing the ion pump and slice was continuously perfused with oxygenated ACSF warmed at $33^{\circ} \mathrm{C}$. Tungsten electrodes (with a tip resistance of 1-3 M $\Omega$ ) were positioned in both the CA1 and CA3 region of the hippocampus. Recordings were made with a World Precision Instruments DAM80 AC amplifier, and acquired using an analog-to-digital converter (Digidata 1322B, Molecular Devices). Analysis was performed using using Clampfit (Molecular Devices) or Matlab (Mathworks)-based software.

\section{Ion pump fabrication and characterization.}

OEIPs were patterned on a glass wafer, which was first cleaned and oxygen plasma treated (Advanced Vacuum Reactive Ion Etch, $\mathrm{O}_{2} 400 \mathrm{sccm}, 250 \mathrm{~W}, 30 \mathrm{~s}$ ). A solution of 3-glycidoxypropyltrimethoxysilane (GOPS, $5 \mathrm{wt} \%$ ) in a water:ethanol mixture (1:19) was 


\section{WILEY-VCH}

spin coated to improve the adhesion of the PSSA-co-MA on glass. After 15 min, the wafers were rinsed in ethanol to remove excess GOPS. They were then baked at $110{ }^{\circ} \mathrm{C}$ for $20 \mathrm{~min}$. PSSA-co-MA (5 wt $\%$ in a water:1-propanol mixture, 1:1) was mixed with polyethylene

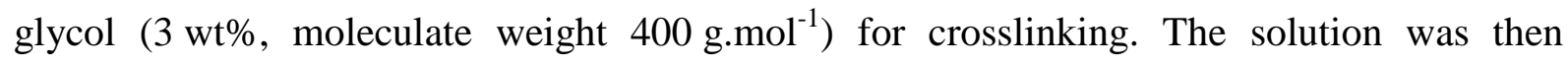
deposited by spin casting at $2000 \mathrm{rpm}$ to obtain a thickness of $400 \mathrm{~nm}$. The film was baked at $110{ }^{\circ} \mathrm{C}$ for $1 \mathrm{~h}$. A thin layer of poly(methyl methacrylate) (PMMA) was deposited on top of the PSSA-co-MA film for a better adhesion of the S1818 photoresist. The photoresist was deposited and exposed using a MA6-BA6 Süss Mask and Bond Aligner and the final pattern was obtained by reactive ion etching $\left(\mathrm{O}_{2} 100 \mathrm{sccm}, \mathrm{CF}_{4} 200 \mathrm{sccm}, 150 \mathrm{~W}, 100 \mathrm{~s}\right)$ and removal of S1818 and PMMA in acetone. Parylene-C was subsequently deposited using an SCS Labcoater 2 to a thickness of $2 \mu \mathrm{m}$ with the use of an adhesion promoting silane. Soap (solution of $1 \%$ in water) was spun and followed by a subsequent parylene-C deposition $(2 \mu \mathrm{m})$. Finally, the source/target PEDOT:PSS was patterned with the insulating parylene-C using photolithography and a sacrificial peel-off step. A thick layer of AZ9260 (MicroChemicals) photoresist was cast, baked and exposed using a SUSS MJB4 contact aligner, followed by reactive ion etching in an $\mathrm{O}_{2}$ plasma $\left(160 \mathrm{~W}, 50 \mathrm{sccm} \mathrm{O}_{2}, 15 \mathrm{~min}\right)$ using an Oxford 80 plus plasma etcher. For the preparation of the PEDOT:PSS films, a $20 \mathrm{ml}$ of aqueous dispersion was made from PEDOT:PSS (PH 1000 from H.C. Stark), $1 \mathrm{ml}$ of ethylene glycol, $50 \mu \mathrm{l}$ of dodecyl benzene sulfonic acid and $1 \mathrm{wt} \%$ of GOPS, and the resulting dispersion was spin-coated at $650 \mathrm{rpm}$, soft baked at $100^{\circ} \mathrm{C}$ for $60 \mathrm{~s}$, and spun cast at $650 \mathrm{rpm}$ to attain thicker PEDOT:PSS films. The film is patterned by peel-off of the top parylene C film and subsequently baked at $140{ }^{\circ} \mathrm{C}$ for $1 \mathrm{~h}$ and were immersed in deionized water to remove any excess low molecular weight compounds. The reservoir chambers, cut from cured polydimethylsiloxane, were affixed to the source (reservoir) and target (bath) areas. During pump operation, voltage $\left(\mathrm{V}_{\text {pump }}=20 \mathrm{~V}\right)$ was sourced and current measured using a Keithley 2400 source/measure unit, and customized LabView software. 


\section{WILEY-VCH}

\section{Acknowledgements}

The research leading to these results has received funding from the European Union's Seventh Framework Programme (FP7/2007-2013) under grant agreement no602102 (EPITARGET) and A*MIDEX project MIDOE (A_M-AAP-ID-13-24-130531-16.31-BERNARD-HLS). Funding was also provided by the Swedish Innovation Office (VINNOVA, 2010-00507), the Swedish Research Council (Vetenskapsrådet, 621-2011-3517), and the Knut and Alice Wallenberg Foundation (KAW Scholar, 2012.0302). The authors would additionally like to acknowledge the National Science foundation grant DMR-1105253 for partial support of this work, the ANR through the project PolyProbe (ANR-13-BSV5-0019-01), Fondation pour la Recherche Médicale under grant agreement DBS20131128446, Fondation de l'Avenir, the Önnesjö Foundation, and the Region PACA, Microvitae Technologies, and Orthogonal, Inc. J.R. and L.K. acknowledge support from Marie Curie Fellowships. The fabrication of the device was performed in part at the Centre Microelectronique de Provence (CMP). The authors thank Gaelle Rondeau and the staff of the clean room in CMP for technical support during the devices fabrication. The authors thank Sophie Lindesvik for incalculable assistance in project administration. Finally, Adam Williamson sincerely thanks Robert Charles Williamson for inspiration.

\section{References}

[1] R. Cecchelli, V. Berezowski, S. Lundquist, M. Culot, M. Renftel, M. Dehouck, L. Fenart, Nature Reviews Drug Discovery, 2007, 6, 650-661.

[2] N. J. Abbott, L. Rönnbäck, E. Hansson, Nature Reviews Neuroscience, 2006, 7, 41-53.

[3] W. Löscher, H. Potschka, Nature Reviews Neuroscience, 2005, 6, 591-602.

[4] C. F. Higgins, Nature, 2007, 446, 749-757.

[5] E. Krook-Magnuson, C. Armstrong, M. Oijala, I. Soltesz, Nature Communications, 2013, 4, 1376.

[6] J. T. Paz, T. J. Davidson, E. S. Frechette, B. Delord, I. Parada, K. Peng, K. Deisseroth, J. R. Huguenard, Nature Neuroscience, 2013, 16, 64-70.

[7] R. C. Wykes, J. H. Heeroma, L. Mantoan, K. Zheng, D. C. MacDonald, K. Deisseroth, K. S. Hashemi, M. C. Walker, S. Schorge, D. M. Kullmann, Sci Transl Med, 2012, 21, 4, 161.

[8] K. Deisseroth, Nature Methods, 2011, 8, 26-29.

[9] K. M. Tye, K. Deisseroth, Nature Reviews Neuroscience, 2012, 13, 251-266.

[10] S. Dong, S. C. Rogan, B. L. Roth, Nature Protocols, 2010, 5, 561-573.

[11] M. S. Farrell, Y. Pei, Y. Wan, P. N. Yadav, T. L. Daigle, D. J. Urban, H. Lee, N. Sciaky, A. Simmons, R. J. Nonneman, X. Huang, S. J. Hufeisen, J. Guettier, S. S. Moy, J. Wess, M. G. Caron, N. Calakos, B. L. Roth, Neuropsychopharmacology, 2013, 38, 854-862. 


\section{WILEY-VCH}

[12] S. M. Ferguson, J. F. Neumaier, Neuropsychopharmacology, 2012, 37, 296-312.

[13] D. M. Kullmann, S. Schorge, M. C. Walker, R. C. Wykes, Nat Rev Neurol, 2014, 10, 5, 300-304.

[14] D. A. LaVan, T. McGuire, R. Langer, Nature Biotechnology, 2003, 21, 1184-1191.

[15] W. M. Saltzman, et al., Nature Reviews Drug Discovery, 2002, 1, 177-186.

[16] R. Wadhwa, C. F. Lagenaur, X. T. Cui, Journal of Controlled Release, 2006, 110, 3, 531-541.

[17] D. Svirskis, J. Travas-Sejdic, A. Rodgers, S. Garg, Journal of Controlled Release, 2010, 146, 1, 6-15.

[18] P. Kwan, S. C. Schachter, M. J. Brodie, N Engl J Med, 2011.

[19] W. Löscher, H. Klitgaard, R. E. Twyman, D. Schmidt, Nature Reviews Drug Discovery, 2013, 12, 757-776.

[20] M. A. Rogawski, W. Löscher, Nature Reviews Neuroscience, 2004, 5, 553-564.

[21] M. Bialer, H. S. White, Nature Reviews Drug Discovery, 2010, 9, 68-82.

[22] K. Albus, A. Wahab, U. Heinemann, British Journal of Pharmacology, 2008, 154, 709724.

[23] A. Wahab, K. Albus, S. Gabriel, U. Heinemann, Epilepsia, 2010, 51, 154-159.

[24] A. Semyanov, M. C. Walker, D. M. Kullmann, Nature Neuroscience, 2003, 6, 484-490.

[25] A. Scimemi, Front Cell Neurosci., 2014, 17, 8, 161, 1-14.

[26] H. S. White, M. D. Smith, K. S. Wilcox, International Review of Neurobiology, 2007, 81, 85-110.

[27] K. K. Madsen, H. S. White, A. Schousboe, Pharmacology \& Therapeutics, 2010, 125, 3, 394-401.

[28] E. Stavrinidou, et al., Adv. Mater., 2013, 25, 4488-4493.

[29] P. A. Rutecki , F. J. Lebeda , D. Johnston, Journal of Neurophysiology, 1985, 54, 5, 1363-1374.

[30] J. L. Stringer, E. W. Lothman, Experimental Neurology, 1988, 101, 1, 147-157.

[31] P. Kofuji, E. A. Newman, Neuroscience, 2004, 129, 4, 1045-1056.

[32] I. Mody , J. D. Lambert , U. Heinemann, Journal of Neurophysiology, 1987, 57, 3, 869888. 


\section{WILEY-VCH}

[33] R. A. Voskuyl, H. Albus, Brain Research, 1985, 342, 1, 54-66.

[34] M. V. Jones, G. L. Westbrook, Neuron, 1995, 15, 1, 181-191.

[35] V. K. Jirsa, W. C. Stacey, P. P. Quilichini, A. I. Ivanov, C. Bernard, Brain, 2014, 137, 2210-2230.

[36] R., C. Bernard, Y. Ben-Ari, Trends in Neuroscience, 2005, 28, 2, 108-115.

[37] C. A. Schevon, S. A. Weiss, G. McKhann Jr, R. R. Goodman, R. Yuste, R. G. Emerson, A. J. Trevelyan, Nature Communications, 2012, 3, 1060.

[38] A. J. Trevelyan, D. Sussillo, B. O. Watson, R. Yuste, J. Neurosci., 2006, 26, $12447-$ 12455 .

[39] A. J. Trevelyan, J. Neurosci., 2009, 29, 15299-15307.

[40] A. J. Trevelyan, D. Sussillo, R. Yuste, J. Neurosci., 2007, 27, 3383-3387.

[41] J. Bormann, Trends in Neurosciences, 1988, 11, 3, 112-116.

[42] D. F. Owens, A. R. Kriegstein, Nature Reviews Neuroscience, 2002, 3, 715-727.

[43] M. V. Jones, G. L. Westbrook, Trends in Neurosciences, 1996, 19, 3, 96-101.

[44] M. V. Jones, P. Jonas, Y. Sahara, G. L. Westbrook, Biophysical Journal, 2001, 81, 26602670 .

[45] J. C. Hirsch, C. Agassandian, A. Merchán-Pérez, Y. Ben-Ari, J. DeFelipe, M. Esclapez, C. Bernard, Nature Neuroscience, 1999, 2, 499-500.

[46] R. Cossart, C. Dinocourt, J. C. Hirsch, A. Merchan-Perez, J. De Felipe, Y. Ben-Ari, M. Esclapez, C. Bernard, Nature Neuroscience, 2001, 4, 52-62.

[47] D. Khodagholy, T. Doublet, P. Quilichini, M. Gurfinkel, P. Leleux, A. Ghestem, E. Ismailova, T. Hervé, S. Sanaur, C. Bernard, G. G. Malliaras, Nature Comm., 2013, 4, 1575.

[48] D. Khodagholy, J. Rivnay, M. Sessolo, M. Gurfinkel, P. Leleux, L. H. Jimison, E. Stavrinidou, T. Herve, S. Sanaur, R. M. Owens, G. G. Malliaras, Nature Comm., 2013, 4, 2133.

[49] D. Khodagholy, T. Doublet, M. Gurfinkel, P. Quilichini, E. Ismailova, P. Leleux, T. Herve, S. Sanaur, C. Bernard, G. G. Malliaras, Adv. Mater., 2011, 23, 268-272.

[50] J. Isaksson, P. Kjäll, D. Nilsson, N. Robinson, M. Berggren, A. Richter-Dahlfors, Nature Materials, 2007, 6, 673-679.

[51] D. T. Simon, S. Kurup, K. C. Larsson, R. Hori, K. Tybrandt, M. Goiny, E. W. H. Jager, M. Berggren, B. Canlon, A. Richter-Dahlfors, Nature Materials, 2009, 8, 742-746. 


\section{WILEY-VCH}

[52] K. Tybrandt, K. C. Larsson, S. Kurup, D. T. Simon, P. Kjäll, J. Isaksson, M. Sandberg, E. W. H. Jager, A. Richter-Dahlfors, M. Berggren, Adv. Mater., 2009, 21, 4442-4446.

[53] M. Antkowiak, M. L. Torres-Mapa, E. C. Witts, G. B. Miles, K. Dholakia, F. J. GunnMoore, Scientific Reports, 2013, 3, 3281, 1-8

[54] R. Marc, R. Pfeiffer, B. Jones, ACS Chem Neurosci, 2014, 5, 10, 895-901

Copyright WILEY-VCH Verlag GmbH \& Co. KGaA, 69469 Weinheim, Germany, 2013. 